
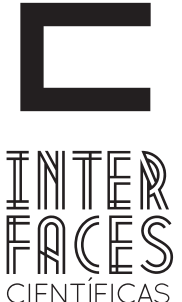

EXATAS E TECNOLÓGICAS

ISSN IMPRESSO - 2359-4934

ISSN ELETRÔNICO - 2359-4942

DOI - 10.17564/2359-4934.2015v1n2p11-20

\title{
O CONHECIMENTO TRADICIONAL E O DESENVOLVIMENTO DE PRODUTOS ARTESANAIS NO CAMPO DO DESIGN
}

Adriana Yumi Sato Duarte ${ }^{1}$

Regina Aparecida Sanches
Marília Colozio Favaro

Franco Guiseppe Dedini ${ }^{4}$

\section{RESUMO}

O objetivo geral da pesquisa é apresentar um ensaio relacionando conhecimentos tradicionais, resgate de cultura e desenvolvimento de produtos artesanais no contexto brasileiro. Para tanto, os procedimentos metodológicos utilizados como base para atingir os objetivos são o referencial teórico acerca dos temas pilares da pesquisa, discussão e correlacionamento dos termos. Como consequência, esta pesquisa aponta um estudo inicial de como o conhecimento tradicional pode ser aplicado no campo do design para desenvolvimento de novos produtos. 0 design pode ser uma forma de englobar o conhecimento tradicional ao desenvolvimento de novos produtos, principalmente por ser uma atividade criativa e interdisciplinar que considera a esfera cultural e o contexto projetual-tecnológico. 0 Craft-Design, que une funcionalida- de, design e artesanato, e o design vernacular, que preza pela prática de desenvolvimento de produto são exemplos da união entre design e artesanato. As dificuldades encontradas na produção artesanal são consideradas pontos de partida para a necessidade de aplicação de um método de intervenção mínima do design que apoie o desenvolvimento de produtos sem negligenciar a história, importância econômica, social, cultural e ambiental que relaciona esta produção aos detentores do conhecimento e técnicas.

\section{PALAVRAS-CHAVE}

Produção Artesanal; Conhecimento Tradicional; Design; Brasil 


\section{ABSTRACT}

The overall objective of the research is to present an essay linking traditional knowledge, culture rescue and development of handicraft products in the Brazilian context. Therefore, the methodological procedures used as a basis for achieving the objectives are the theoretical framework about the pillars themes of research, discussion and correlating the terms. As a result, this research points out an initial study of how traditional knowledge can be applied in the field of design for new product development. The design can be a way to encompass traditional knowledge to the development of new products, mainly because it is a creative and interdisciplinary activity that considers the cultural sphere and the architectural design and technological context. The Craft-Design, which combines functionality, design

\section{RESUMEN}

Esta investigación tiene como objetivo discutir los conocimientos tradicionales, rescatar la cultura y la producción artesanal en Brasil. Para lograr este objetivo, se presenta un marco teórico sobre los temas de investigación, el debate y la vinculación entre ellos. Como resultado, esta investigación indica un estudio inicial de cómo el conocimiento tradicional se puede aplicar en el campo del design para el desarrollo de productos. El design puede ser una manera de abarcar los conocimientos tradicionales con el proceso de desarrollo de productos, sobre todo porque es una actividad creativa e interdisciplinaria que considera la cultural y los contextos tecnológicos. El Craft-Design, que combina la funcionalidad, el design y la and craftsmanship, and the vernacular design, which values the product development practice are examples of the union of design and craftsmanship. The difficulties encountered in craft production are considered starting points to the need to apply a minimum design intervention methods to support product development without neglecting the history, economic importance, social, cultural and environmental production that relates this to the holders of knowledge and techniques.

\section{KEYWORDS}

Handcraft Production. Traditional Knowledge. Design. Brazil.

artesanía, y el design vernáculo que valora las prácticas de desarrollo de productos son ejemplos de la unión entre el design y la producción de artesanías. Los obstáculos en la producción artesanal se consideran puntos de inicio para aplicar un método de design de mínima intervención para apoyar el desarrollo de productos sin olvidar la historia, los aspectos económicos, sociales, culturales y ambientales.

\section{PALABRAS CLAVE}

Producción artesanal; Conocimiento tradicional; Diseño; Brasil. 


\section{INTRODUCÃO}

A atividade artesanal surge como tema importante por ser considerada, ao mesmo tempo, tradicional e atemporal. Vista não apenas como uma forma de sobrevivência econômica é uma atividade que demanda habilidades específicas, inerentes ao indivíduo que a pratica. Na sociedade contemporânea, a atividade artesanal atende a um mercado advindo do "ressurgimento" do objeto artesanal, carregado com valores culturais, sociais e estéticos. É uma atividade intersetorial associada a diversas outras atividades econômicas afins, como a moda, arquitetura e decoração.

O tema é paradoxo, pois se o processo produtivo da sociedade contemporânea prevê uma homogeneização da cultura, ao mesmo tempo, premia a constante diferenciação dos produtos, no ciclo conhecido como "obsolescência programada". A atividade artesanal neste cenário está em constante conflito entre a globalização e localidade, por transcender a repetição formal para atingir a releitura.

Neste cenário, uma abordagem sistemática é necessária para vislumbrar a documentação da atividade, que inicia pelo estudo sociocultural do grupo que domina uma técnica e atinge a produção formal, com a descrição da técnica e materiais, fornecendo dados importantes tanto para pesquisadores quanto para 0 grupo produtor, ao se tornar uma forma de manutenção do conhecimento e memória coletiva. No caso do Brasil, políticas públicas para estímulo da produção e parcerias Público-Privado formaram o pilar de reposicionamento da produção artesanal em um mercado mais competitivo.

Da descrição deste cenário emergiu a possibilidade de desenvolver novos produtos, mantendo técnicas e tradições artesanais, de forma sistematizada e apoiada pela teoria do design amplamente utilizada em diferentes setores do conhecimento humano. Sobre o tema, poucos autores fazem referência à evo- lução metodológica utilizada no desenvolvimento de novos produtos artesanais.

Desta forma, o objetivo geral da presente pesquisa é apresentar um ensaio, relacionando conhecimentos tradicionais, resgate de cultura e desenvolvimento de produtos artesanais. Para tanto, os procedimentos metodológicos utilizados como base para atingir os objetivos são o referencial teórico acerca dos temas pilares da pesquisa - produção artesanal brasileira, contexto histórico do design e desenvolvimento de produto - além da discussão e correlacionamento entre os termos.

\section{CONCEITUAÇ̃̃O DE PRODUÇÃO ARTESANAL}

O homem, como outros animais, tem a capacidade de transformar e modificar o ambiente ao seu redor para melhor atender suas necessidades e demandas (PAPANEK, 2000). No entanto, é a produção de bens duráveis e de uso diário que melhor expressa a natureza humana, que por meio do trabalho potencializa sua capacidade criativa e produtiva (SANTOS ET AL., 2010).

Desde o princípio da história da humanidade, o indivíduo que detinha uma habilidade manual era treinado e, após passar por um programa de aprendizado, se tornava Mestre da Arte (CASSAGNES-BROUQUET, 2010). 0 conhecimento e métodos utilizados eram refinados a partir da experiência pessoal e transmitidos, da mesma maneira, para outros aprendizes. Muitos destes métodos e conhecimentos foram adquiridos por meio de experimentações, construção de protótipos e reprojeto. Entretanto, com esta metodologia, os produtos eram modificados e atingiam maturidade somente após muitas gerações (ULLMAN, 2002).

Etimologicamente, a palavra artesanato tem origem do Latim "ars" que significa a capacidade de fazer algo, e que mais tarde assumiu o significado Arte. 
Artesão, deriva do italiano “Artigiano”, relacionado à pessoa que exerce atividades manuais para construção de objetos domésticos. Esse termo foi empregado na Antiguidade, e permanece em uso até os dias de hoje.

Vidal e Silva (1995) afirmam que os objetos remetem às tradições específicas da identidade do grupo produtor, trazem os modos de viver e pensar do presente e as relações com o patrimônio cultural do grupo.

No aspecto econômico, o modelo de produção artesanal é expresso por um sistema auto-organizado, que dá liberdade ao artesão de criar seu próprio padrão de trabalho, mas limita a atuação do artesão em um mercado mais competitivo (MATURANA ET AL., 2011). Este modelo econômico estimula o Desenvolvimento Local (DL), um conjunto de iniciativas e decisões a serem tomadas para melhoria do bem-estar coletivo, valorizando pontos fortes, potencial intelectual dos habitantes e contexto sociocultural-histórico em que estão envolvidos, e o Arranjo Produtivo Local (APL), ao agregar um conjunto de atividades em um núcleo familiar e colaborativo formado a partir do compartilhamento de experiências e informações (SANTOS ET AL., 2010).

No âmbito social, o artesanato tem relação com a expressão do criador ao reconhecer outros membros do grupo e transmitir às gerações futuras de forma oral o conhecimento tradicional particular de seu povo (SANTOS ET AL., 2010; SATO DUARTE ET AL., 2012).

O aspecto ambiental é contemplado no uso de matérias-primas regionais, cuja proximidade e facilidade de acesso permitem uma minimização do impacto causado pelo deslocamento e transporte do insumo até a produção. Outro ponto chave da questão ambiental é o conhecimento do artesão sobre as características dos materiais utilizados na confecção das peças (SATO DUARTE ET AL., 2012).

Nos primeiros anos de colonização do Brasil, o estímulo ao desenvolvimento de oficinas artesanais partiu da necessidade de produzir objetos funcionais, e como consequência, a iniciativa se popularizou e multiplicou a presença de comunidades rurais e urbanas (MARTINS, 1973).

0 artesanato no Brasil foi reconhecido formalmente a partir da década de 1950. Associado a uma atividade inferior, voltado para programas assistencialistas e de inclusão social e econômico, o artesanato esteve excluído do mercado nacional por um longo período de tempo.

As primeiras iniciativas para a formalização do setor, a partir dos anos 1950, visavam duas linhas de raciocínio diferentes: educação e estruturação baseada no planejamento econômico. 0 pensamento educativo incentivava o desenvolvimento local, principalmente na zona rural, de forma a complementar a renda familiar. Para estruturar o setor, a capacitação dos produtores em parceria com órgãos públicos e pesquisadores de todo o País permitiram criar um padrão estético refinado (SERAINE, 2009) e, como efeito, impulsionou a conscientização da problemática do artesanato, difundindo suas ideias, abrindo mercados e fortalecendo os produtores elevando, assim, a um patamar de relevância econômica e social (PEREIRA, 1979).

Após esta iniciativa, diversos projetos semelhantes foram desenvolvidos regionalmente, em caráter experimental, de acordo com a atividade realizada. A criação do Instituto de Pesquisas e Treinamento do Artesanato (IPTA) em 1957, pesquisas do Banco do Nordeste do Brasil (BNB) em 1958, assistência por parte do Conselho de Desenvolvimento Econômico de Sergipe (CONDESE) nos anos 1960, experiências no Estado do Rio Grande do Norte, criação da Artesanato do Nordeste S/A (ARTENE) em 1961 e o Projeto de Assistência ao Artesanato Brasileiro (PAAB), também do ano de 1961 são exemplos das tentativas de resgatar e difundir as técnicas artesanais para o País.

A partir do ano de 1995, o Serviço de Apoio à Micro e Pequenas Empresas (SEBRAE) criou o Programa 
SEBRAE de Artesanato (PSA), atuante até os dias de hoje. Na visão do SEBRAE, o artesanato é uma atividade que gera renda e empregos, e como tal, requer tratamento empresarial. Por este motivo, utiliza estratégias como ampliação de oportunidades e acesso ao crédito e capital, formalização do setor, aumento da produção por meio do acesso à tecnologia e incentivo à inovação, formação do pensamento empreendedor dirigido aos artesãos, resgate de cultura e identidade local, educação ambiental e uso racional de recursos naturais e estabelecimento de estratégias, plano de negócios e ferramentas metodológicas para aumentar a competitividade (SEBRAE, 2004).

Em pesquisa realizada durante o ano de 2009, este setor no Brasil empregou 8.5 milhões de artesãos, com faturamento médio mensal de um salário mínimo, gerando arrecadação bruta de R\$52 bilhões ao ano. Os dados coletados demonstraram que os artigos utilitários são a principal categoria da produção artesanal (69\%), seguido de roupas (57\%), admitindo que cada artesão produz mais de um tipo de produto.

O faturamento médio dos últimos seis meses anteriores à pesquisa foi de $\mathrm{R} \$ 10.127,14$. Quando comparados dados de 2005 a 2010, é notável o crescimento contínuo da produção de roupas, e a produção de artigos utilitários é a categoria mais relevante do artesanato em geral (VOX POPULI, 2010).

\section{CONHECIMENTO TRADICIONAL E PRODUÇ̃̃O ARTESANAL}

A produção em massa de objetos para consumo imediato e a busca por novos materiais geram impactos perceptíveis e imperceptíveis para o ambiente e sociedade, principalmente àqueles que, diretamente, subsistem de recursos naturais locais (FINKIELSZTEJN, 2006). Essa parcela da sociedade detém conhecimentos específicos sobre manejo, técnicas de transformação de matéria-prima e dinâmica do ecossistema, permitindo o desenvolvimento de siste- mas econômicos, sociais e culturais compatíveis com o ambiente em que está inserida.

Estas comunidades apresentam, além do conhecimento e sistemas compatíveis com o ambiente (memória étnica), técnicas manuais passadas entre gerações (memória técnica). A produção artesanal tem forte ligação com o conhecimento tradicional e a tradição oral. O conhecimento tradicional inclui diferentes formas de expressão cultural, assim como o conhecimento biológico, inovações e práticas.

Estas diferentes formas de manifestação cultural podem ser entendidas como patrimônio cultural imaterial que, segundo a "Convenção para a Salvaguarda do Patrimônio Cultural Imaterial”, é caracterizado como "práticas, representações, expressões, conhecimento e técnicas - junto com instrumentos, objetos, artefatos e lugares culturais que lhes são associados", transmitidos de geração em geração e constantemente recriados e inovados em função da necessidade e/ou ambiente ao redor. Essa Convenção indicou o uso do termo "salvaguarda" com intuito de alertar a necessidade de identificar, documentar, preservar e promover o patrimônio cultural imaterial (IPHAN, 2003).

Diversos autores relatam a importância da preservação do conhecimento tradicional. Zanirato e Ribeiro (2007) afirmam que o conhecimento tradicional resulta do convívio social, carregando o passado para uni-lo ao presente e mantê-lo no futuro, em um sistema vivo e dinâmico; estes autores indicam o reconhecimento dos direitos das comunidades e direitos humanos como forma de preservação do conhecimento tradicional.

Santilli (2005) relata que o conhecimento tradicional sobre propriedades farmacêuticas e alimentícias são fontes de inovação destes produtos. Pereira e Diegues (2010) acreditam que a valorização do conhecimento tradicional é uma alternativa de auxiliar a preservação de ambientes naturais remanescentes e defendem o uso do 
termo "etnoconservação", um conceito que foca as questões relacionadas à proteção de áreas naturais e populações tradicionais de modo a inserir uma nova perspectiva de manejo sustentado por estas populações.

Já Forsyth (2013) sugere alguns mecanismos para gerar oportunidades e desafios para o conhecimento tradicional como limitar o uso do conhecimento tradicional, promover o uso e aumentar a atribuição popular do conhecimento tradicional, estabelecer e reforçar um regime de autorizações de pesquisa para pesquisadores estrangeiros, abranger uma variedade de beneficiários no acesso e partilha de benefícios do uso do conhecimento tradicional, estabelecer a autenticidade do uso do conhecimento tradicional, introduzir controles na importação de produtos artesanais, desenvolver protocolos e diretrizes para o uso do conhecimento tradicional, desenvolver parceria com organizações não governamentais internacionais e acadêmicas que monitoram casos de biopirataria e apoiar festivais culturais.

A conservação da biodiversidade, também, é contemplada no conhecimento tradicional. Mudanças nos modelos que abordam a conservação da biodiversidade ocorreram a partir da década de 1980, quando as populações locais foram consideradas como parte integrante da importância biológica de uma região, considerados "atores da natureza" conforme definição dada por Moreira (2007).

As populações humanas contribuem de forma ativa para a manutenção dos saberes ecológicos e de manejo ao complementarem e, muitas vezes, contradizerem o conhecimento científico com suas práticas e experiências resultantes da vivência diária no ecossistema. Assim, Hanazaki (2003) afirma que os efeitos que destas populações no ecossistema são quantitativa e qualitativamente menores do que os efeitos causados pela sociedade urbana.

\section{CONHECIMENTO TRADICIONAL E PRODUÇÃO ARTESANAL NO CONTEXTO DO DESIGN}

Design, de acordo com o International Council of Societies of Industrial Design (ICSID), é uma atividade criativa cujo objetivo é estabelecer qualidades multifacetadas de objetos, processos, serviços e ciclos de vidas, sendo o fator central da humanização da tecnologia e crucial para o intercâmbio cultural e econômico (ICSID, 2000).

No design são encontradas duas bases fundamentais: a esfera cultural, com os desdobramentos dos valores vigentes da sociedade, e outra que preza pelo contexto projetual-tecnológico, que abrange desde a produção artesanal e tradicional à industrial. 0 design é uma qualidade adicional na busca pela valorização cultural de um produto ou até no resgate da tradição que, progressivamente, é perdida dentro de uma comunidade. Desta interação, resultam o reconhecimento da importância do valor e o fortalecimento da identidade cultural coletiva (FERREIRA, 2006).

Roizenbruch (2009) afirma que artesanato e design são atividades complementares. Se de um lado o conhecimento da matéria-prima e técnicas manuais pertence ao artesão, a informação, racionalização e contato com mercado são inerentes ao design. Assim, dessa união surgem vantagens materiais como a atualização, racionalização, ampliação e adequação dos materiais utilizados, e vantagens sociais com a afirmação estética e sustentabilidade econômica da atividade.

Ihatsu (1997) descreve uma categoria do design denominado Craft-Design, em que os produtos apresentam as características de funcionalidade, estética e acabamento em produção de peças únicas ou em edições limitadas. Para o autor, no Craft-Design a "função combina, ao invés de separar, as palavras design e artesanato" (IHATSU, 1997, p. 302). 
Existe, ainda, outra categoria do design denominada "vernacular". Este termo foi aplicado, segundo Scott (1857) em uma publicação inglesa sobre arquitetura, como sinônimo de popular ou folclórico. Em uma abordagem mais recente, Finizola e outros autores (2012) afirmam que o design vernacular pode ser definido pelas práticas de desenvolvimento de produto por artistas anônimos e distinguem três grupos principais de artistas: (a) os que fazem releitura ou transpor os elementos visuais presentes na linguagem da região e propõe novas aplicações e usos; (b) aqueles que registram por meio de imagens, cores, texturas, formas e fragmentos do ambiente em torno e (c) os que projetam com abordagem conceitual sobre o tema, porém sem conexão direta com o popular. Já Bonsiepe (2011) descreve que as formas de apropriação de elementos culturais podem ter relação com a conservação, estética, processo produtivo, cultura ou inovação quando se planeja integrar artesanato e design.

Ferreira (2006) afirma que a intervenção em comunidades locais tende a preservar os processos produtivos originais, em uma interferência mínima conforme define Botelho (2005). A possibilidade de descaracterização e aculturação dos produtos e experiências anteriores mal sucedidas são argumentos para o temor da intervenção do design na atividade artesanal. 0 design, ao interagir com o artesanato ou outra forma de manifestação cultural, passa por um processo de hibridização, gerando novas estruturas, antes inexploradas. Por intermédio do design híbrido, tendo como base a metodologia de projeto de produto, nos aproximamos da essência da pesquisa: a iminência de inovação tecnológica e incorporação de técnicas artesanais tradicionais.

No Brasil, assim como a formalização do setor artesanal, o design passou a ter visibilidade a partir da década de 1950 para atender a demanda por profissionais especializados no desenvolvimento de projetos e produtos, estimulado por um período propício ao crescimento industrial a partir do cenário da união da estabilidade econômica e promessa de futuro promissor no país (ROIZENBRUCH, 2009).

Os primeiros professores de design no Brasil foram influenciados pela estética Ulminiana e racionalista, advinda da Bauhaus, em que prevaleciam formas retilíneas e tons acromáticos sem, no entanto, considerar a realidade brasileira (ROIZENBRUCH, 2009). Moraes e Branzi (2006) afirmam que o design brasileiro não promoveu durante sua implantação no País uma compreensão local que proporcionasse a formação de um modelo autônomo, reconhecido como genuinamente brasileiro. Por este motivo, é possível perceber que o modelo racionalista é mais encontrado no movimento de design brasileiro do que os próprios símbolos locais.

Já no final dos anos 1960 e 1970, o Brasil passou por um período em que o binômio política-economia permitiu o "milagre econômico" com a expansão do mercado interno e a possibilidade de destinar a produção para abastecimento local. Todavia, a competição entre as indústrias se restringiu ao território nacional, e com isso o design não se desenvolveu. Percebeu-se, e ainda esta prática é muito comum nos dias de hoje, que as indústrias brasileiras mantinham departamentos de Projeto somente para adaptar os produtos importados para o mercado brasileiro.

Moraes e Branzi (2006) citam o termo "tropicalização de produtos" para a prática de cópia e adaptação para produção e comercialização do produto. Ao passo que a industrialização no Brasil crescia em ritmo acelerado, o design nestas indústrias se distanciava do adequado para o mercado local.

Entretanto, existem relatos de intervenções bem sucedidas do design em comunidades brasileiras que produzem objetos artesanais. A sistematização das pinturas em cuias realizada no ano 2000 pelo Centro Nacional de Folclore e Cultura Popular, e o projeto "Arte Baniwa" para registro de grafismos encontrados nas cestarias produzidas pelos índios Baniwa, reali- 
zado pelo Instituto Socioambiental, são exemplos de intervenções que trouxeram benefícios tanto para os produtores locais quanto para os consumidores desta arte (BORGES, 2011).

\section{CONSIDERAÇÕES FINAIS}

Em termos gerais, a produção artesanal é entendida como uma atividade que transforma a matéria-prima em um produto por meio da aplicação de técnicas manuais adquiridas ao longo da vida do artesão seja de maneira formal ou por experimentação. Uma das principais características desta produção é o conhecimento tradicional, resultante do convívio social e do contexto sociocultural em que os artesãos estão inseridos.

Aspectos ambientais, culturais, sociais, históricos e econômicos são necessários para entender a essência do objeto artesanal. Cabe ressaltar que todos estes aspectos são indissociáveis e, portanto, influenciam e são influenciados pela produção artesanal. No Brasil, a tradição em produzir artesanalmente pode ser considerada relativamente jovem, pois foi formalizada somente na década de 1950. A princípio, este setor era visto apenas como uma fonte alternativa de geração de renda, porém com o ressurgimento do objeto artesanal carregado com valores culturais, sociais e estéticos vem sendo valorizado e integrado a diferentes setores econômicos.

Assim, o design pode ser uma forma de englobar o conhecimento tradicional ao desenvolvimento de novos produtos, principalmente por ser uma atividade criativa e interdisciplinar que considera a esfera cultural e o contexto projetual-tecnológico. 0 Craft-Design, que une funcionalidade, design e artesanato e o design vernacular, que preza pela prática de desenvolvimento de produto são exemplos da união entre design e artesanato.

Diversas intervenções do design na produção artesanal foram descritas na literatura, entretanto o que se pretendeu no presente trabalho é indicar que uma técnica já praticada, com a intervenção do design, pode gerar produtos diferentes dos existentes e trazer benefícios para produtores locais e consumidores. As dificuldades encontradas na produção artesanal são consideradas pontos de partida para a necessidade de aplicação de um método de intervenção mínima do design, que apoie o desenvolvimento de produtos sem negligenciar a história, importância econômica, social, cultural e ambiental que relaciona esta produção aos detentores do conhecimento e técnicas.

\section{REFERÊNCIAS}

BONSIEPE, Gui. Design, cultura e sociedade. São Paulo: Edgar Blucher, 2011. 229p.

BORGES, Adélia. Design + Artesanato: o caminho brasileiro. São Paulo: Terceiro Nome, 2011.

BOTELHO, Vinicius Simões. Design e Artesanato: um estudo comparativo sobre os modelos de intervenção. Universidade Federal de Pernambuco, 2005. 83p.

CASSAGNES-BROUQUET, Sophie. Les métiers au Moyen Age. Paris: Ouest-France, 2010.

FERREIRA, Eliza. 0 design como estratégia de inovação para a competitividade e sustentabilidade de países, empresas e comunidades. Brasilia: Universidade de Brasília, 2006.

FINIZOLA, Fátima; COUTINHO, Solange; CAVALCANTI, Virgínia. Vernacular Design: a discussion on its concept. In: Design Frontiers: territories, concepts, technologies. 617p. Blucher: São Paulo. 2012 .

FINKIELSZTEJN, Beatriz. Sistemas modulares têxteis como aproveitamento de fibras naturais: uma alternativa sustentável em arquitetura \& design. Rio de Janeiro: Pontifícia Universidade Católica, 2006. 
FORSYTH, Miranda. How Can Traditional Knowledge Best Be Regulated? Comparing a Proprietary Rights Approach with a Regulatory Toolbox Approach. The Contemporary Pacific, v.25, n.1, 2013. p.1-31.

HANAZAKI, Natalia. Comunidades, conservação e manejo: o papel do conhecimento ecológico local. Biotemas, v.16, n.1, 2003. p.23-47.

IHATSU, Anna-Marja. Craft, art or design? In pursuit of the changing concept of craft. Vaasa: NordFo, 1997.

ICSID - International Council of Societies of Industrial Design .Design definition. 2000. Disponível em: <http://www.icsid.org/>. Acesso em: 22 ago. 2014.

IPHAN - Instituto do Patrimônio Histórico e Artístico Nacional. Convenção da Salvaguarda do Patrimônio Cultural Imaterial. IPHAN, 2003.

MARTINS, Saul. Contribuição ao estudo científico do artesanato. Imprensa Oficial do Estado de Minas Gerais, 1973.

MATURANA, Humberto; MAGRO, Cristina; PAREDES, Victor. Cognição, ciência e vida cotidiana. Belo Horizonte: UFMG, 2001.

MOREIRA, Eliane. Conhecimento tradicional e a proteção. T\&C Amazônia, v.5, n.11, Manaus, 2007. p.33-41.

MORAES, Dijon; BRANZI, Andrea. Análise do design brasileiro: entre mimese e mestiçagem. São Paulo: Edgard Blücher, 2006.

PAPANEK, Victor. Design for the real world. New York: Thames and Hudson, 2000.

PEREIRA, Carlos José da Costa. Artesanato, definições e evolução: ação do MTb, PNDA. Ministério do Trabalho, Secretaria Geral, 1979
PEREIRA, Bárbara Elisa; DIEGUES, Antonio Carlos. Conhecimento de populações tradicionais como possibilidade de conservação da natureza: uma reflexão sobre a perspectiva da etnoconservação. Desenvolvimento e Meio Ambiente, v.22, n.1, 2010.

ROIZENBRUCH, Tatiana Azzi. 0 jogo das diferenças: design e arte popular no cenário multicultural brasileiro. Universidade Anhembi Morumbi, 2009.

SANTILLI, Juliana. Socioambientalismo e novos direitos. São Paulo: Peirópolis, 2005.

SANTOS, Thiago de Sousa et al. O artesanato como elemento impulsionador no desenvolvimento local em municípios brasileiros. Anais do VII Simpósio de Excelência de Gestão e Tecnologia, 2010.

SATO DUARTE, Adriana et al. Ethnobotany of natural fibres-bactris setosa (tucum) in a traditional rural community. Fibres \& Textiles in Eastern Europe, 2012.

SEBRAE - Serviço de Apoio às Micro e Pequenas Empresas. Programa SEBRAE de artesanato: Termo de referência. Brasília: SEBRAE, 2004.

SERAINE, Ana Beatriz Martins dos Santos. Ressignificação produtiva do setor artesanal na década de 1990: o encontro entre artesanato e empreendedorismo. Campinas: Universidade Estadual de Campinas, 2009

ULLMAN, David. The Mechanical Design Process. McGraw-Hill: New York. 2002.

VIDAL, Lux; SILVA, Aracy Lopes da. O sistema de objetos nas sociedades indígenas: arte e cultura material. In: SILVA, Aracy Lopes da e GRUPIONI, Luís Donisete B. (Orgs.). A Temática Indígena na Escola. Ministério da Educação e do Desporto, 1995. 
VOX POPULI. Relatório de pesquisa: Centro Cape. 2010.

ZANIRATO, Silvia Helena; RIBEIRO, Wagner Costa.

Conhecimento tradicional e propriedade intelectual nas organizações multilaterais. Ambiente \& Sociedade, v.10, n.1, 2007. p.39-55. 